\title{
A TRANSPOSIÇÃO DIDÁTICA NA ELABORAÇÃO DE UM OBJETO DE APRENDIZAGEM NO GEOGEBRA
}

\section{The Didactic Transposition in the Elaboration of a Learning Object in GeoGebra}

\author{
Stephanie Diaz-Urdaneta* \\ Marco Aurélio Kalinke** \\ Marcelo Souza Motta***
}

\begin{abstract}
Resumo: O objetivo deste trabalho é descrever como questões da teoria da Transposição Didática estão presentes na construção de um Objeto de Aprendizagem no GeoGebra e algumas contribuições disso na Educação Matemática com Tecnologias Digitais. Para isso, apresenta-se o que se compreendem como Objetos de Aprendizagem e os diferentes processos e ações no processo da Transposição Didática. Na sequência, descreve-se como essas questões teóricas estiveram presentes na elaboração do simulador, o qual é compreendido como um Objeto de Aprendizagem. Na descrição, evidenciou-se que parte dos processos e ações da Transposição Didática estiveram presentes na elaboração, mesmo que ele não tenha sido idealizado à luz desta teoria. Neste sentido, conclui-se que na utilização das Tecnologias Digitais na Educação da Matemática é possível perceber características da Transposição Didática.
\end{abstract}

Palavras-chave: Transposição Didática; Objeto de Aprendizagem; GeoGebra.

\begin{abstract}
The aim of this paper is to describe how issues of Didactic Transposition theory are present in the construction of a Learning Object with GeoGebra and its contributions to Mathematical Education with Digital Technologies. For this, there was presented what is understood as Learning Objects and the different processes and actions in the Didactic Transposition process. Later, it was described how these theoretical issues were present in the elaboration of the simulator, which is seen as a Learning Object. In the description, it was evidenced that part of the processes and actions of Didactic Transposition were present in the elaboration, even though it was not idealized in the light of this theory. In this sense, it is concluded that in the use of Digital Technologies in Mathematics Education it is possible to perceive characteristics of Didactic Transposition.
\end{abstract}

Keywords: Didactic Transposition; Learning Object; GeoGebra.

\footnotetext{
* Mestranda do Programa de Pós-graduação em Educação em Ciência e Matemática da Universidade Federal do Paraná (PPGECM - UFPR). Orcid: https://orcid.org/0000-0002-8335-2022. E-mail: stephaniediazurdaneta@gmail.com

** Doutor em Educação Matemática e professor da Universidade Tecnológica Federal do Paraná (UTFPR) Câmpus Curitiba. Orcid: http://orcid.org/0000-0002-5484-1724. E-mail: marcokalinke@ yahoo.com.br

*** Doutor em Ensino de Ciências e Matemática e professor da Universidade Tecnológica Federal do Paraná (UTFPR) - Câmpus Curitiba. Orcid: http://orcid.org/0000-0001-5534-2735. E-mail: marcelomotta@utfpr.edu.br.
} 


\section{Introdução}

Esse texto é produto de reflexões que giram em torno das ideias da Transposição Didática de Yves Chevallard (1991) e das experiências de pesquisa dos autores em relação às Tecnologias Digitais (TD) na Educação Matemática, que têm sido desenvolvidas no âmbito do Programa de Pós-graduação em Educação em Ciências e em Matemática (PPGECM) da Universidade Federal do Paraná (UFPR) e no Grupo de Pesquisa sobre Tecnologias na Educação Matemática (GPTEM), dos quais fazem parte.

Um dos aspectos presentes nas pesquisas às quais os autores direcionam seus olhares é como o professor que usa as TD em uma aula de Matemática ou na preparação dos materiais a serem nela utilizados, considera os aspectos da Transposição Didática. Diversos autores têm se dedicado a estudar a influência das TD na Educação Matemática (OBATA; MOCROSKY; KALINKE, 2018; MOTTA, 2018; VILLA-OCHOA, 2016; ARTIGUE, 2011; PAZUCH, BATTISTI; NEHRING，2011; VILLARREAL，2012; RIVEROS; MENDOZA; CASTRO, 2011) e a literatura relativa à esta questão traz algumas compreensões sobre o assunto, mas a inquietação sobre a Transposição Didática quando se usa as TD é uma questão de interesse que ainda carece de mais análises e aprofundamentos, particularmente pela dinâmica de desenvolvimento e construção de recursos tecnológicos digitais (ALMOULOUD, 2010).

Com base no exposto, e para contribuir com a temática apresentada, neste trabalho se fará a descrição de como questões de Transposição Didática estão presentes na elaboração de um Objeto de Aprendizagem no GeoGebra chamado "Movimento Rectilíneo Uniforme" e algumas contribuições disso para a Educação Matemática. Com isto, procura-se contribuir com compreensões sobre o assunto e somar conhecimentos à discussão proposta.

\section{A transposição didática}

As discussões realizadas sobre a Transposição Didática estão presentes em vários trabalhos, ainda que com diversas abordagens. Alguns dedicam-se a fazer reflexões sobre os seus conceitos teóricos (CARDELLI, 2004; GÓMEZ MENDOZA, 2005; RAMÍREZ BRAVO, 2005), outros destacam diferentes olhares (NEVES; BARROS, 2011; JARDIM; CAMARGO; ZIMER, 2015). Fernández Caraballo (2002) discutiu ideias sobre a proposta epistemológica de Yves Chevallard, e outros autores se dedicam a cultura na Transposição Didática das Ciências (MONTEIRO; KRUGUER, 2009). No Brasil, o livro Didática da Matemática (PAIS, 2001) apresenta um de seus capítulos relacionado à Transposição Didática na compreensão de Chevallard.

As reflexões sobre o conceito dessa teoria, os diferentes processos e ações que se põem em pauta quando se faz uso dela, os diferentes atores que influenciam seus processos e como ela pode ser compreendida culturalmente; contribuíram em discussões mais amplas que nos ajudaram a adquirir compressões em relação à Transposição Didática. Nessas reflexões surgiu a inquietação sobre o seu papel quando se faz uso das TD. Para tentar compreender a relação entre elas, apresentam-se as ideias básicas da Transposição Didática, os processos e ações que se evidenciam nela e os diferentes agentes que influenciam nessas questões a serem apresentadas.

Com relação ao conceito de Transposição Didática, alguns autores indicam que foi Michel Verret quem a introduziu (GÓMEZ MENDOZA, 2005; RAMÍREZ BRAVO, 2005).

\footnotetext{
${ }^{1}$ Disponível em: https://www.geogebra.org/m/sUZxZPeP. Acesso em: 10 maio 2019
} 
Segundo Verret (1975, apud GÓMEZ MENDOZA, 2005) a Transposição Didática é “A transmissão daqueles que sabem àqueles que não sabem. Daqueles que aprenderam para aqueles que aprendem" (VERRET, 1975, p. 139. Tradução nossa). Depois, Yves Chevallard retomou esse termo em 1985 com a primeira edição do seu livro sobre a Transposição Didática (GÓMEZ MENDOZA, 2005; MORA CASTIBLANCO, 2014).

Em Chevallard (1991), encontramos:

\begin{abstract}
Um conteúdo de saber que foi designado como saber a ensinar, sofre então um conjunto de transformações adaptativas que vão torná-lo apto para ocupar um lugar entre objetos de ensino. $\mathrm{O}$ "trabalho" que transforma um objeto de saber a ensinar em objeto de ensino, é chamado de transposição didática. (CHEVALLARD, 1991, p. 17. Tradução nossa).
\end{abstract}

Ramírez Bravo (2005) destaca a existência de certos processos pelos quais transita o objeto do saber para se converter em objeto de ensino. Tais processos são os seguintes:

a) Descontextualização: recontextualização do saber.

b) Despersonalização: separação do saber de quem o produziu e do saber científico.

c) Programação: sequenciação da aquisição do saber, classificação dos conteúdos, temporalização, etc.

d) Controle social da aprendizagem: valoração e verificação dos procedimentos na obtenção e distribuição dos saberes para garantir o valor conceitual das noções nos contextos.

e) Publicidade: promoção dos saberes selecionados para o ensino por meio do currículo, livros escolares, projetos, planejamentos de aulas e materiais escolares em geral.

Diante disso, compreende-se que para a consolidação desses processos da Transposição Didática tem que estar presente um conjunto de ações que se manifestam no trabalho, que vão desde o objeto do saber até o objeto de ensino. Tais ações são as propostas por RAMÍREZ BRAVO (2005) e dividem-se em:

a) Selecionar e extrair de um saber maior, os temas disciplinares.

b) Reduzir as informações dos saberes maiores de forma que possam ser ajustados aos aspectos didáticos do contexto.

c) Simplificar as informações para fazê-las mais simples através de estratégias, técnicas e atividades adequadas para o desenvolvimento das aulas.

d) Reformular os saberes científicos em saberes a serem ensinados através das reconstruções do saber, identificação de insuficiências estruturais e conceituais.

Segundo Pais (2001) nessa trajetória do objeto de saber até o objeto de ensino, que envolve esses processos e ações apresentadas nas linhas anteriores, pode-se visualizar os autores que a influenciam: cientistas, professores, especialistas, políticos, autores de livros, dentre outros, os quais contribuem na reformulação de aspectos conceituais do saber e a forma como eles são apresentados. No caso do professor, ele é considerado como um dos responsáveis pela Transposição Didática, sendo quem faz a interpretação dos saberes para reformulá-los em saberes escolares e, além disso, é o carregado pela programação desses saberes no planejamento escolar (RAMÍREZ BRAVO, 2005).

Entende-se que o professor tem um papel fundamental no processo de Transposição Didática porque é no momento do planejamento da aula que, geralmente, ele faz a seleção dos saberes necessários, considerando a turma e as bases curriculares que regem o sistema 
educativo em que ele se encontra. É ele também que reorganiza as informações, muitas das vezes recontextualizando-as segundo seu entorno, estrutura o conteúdo através de seu método de ensino e depois faz a reformulação dos conceitos que serão discutidos na aula, buscando que eles conservem suas noções principais.

Neste sentido, tentando visualizar esses processos e ações quando se usa as TD na Educação Matemática, na sequência apresentaremos como algumas dessas questões da teoria da Transposição Didática estão presentes na elaboração de um Objeto de Aprendizagem no GeoGebra.

\section{Metodologia}

Para o desenvolvimento do trabalho aqui proposto, utilizou-se o trabalho de Diaz e Rubio (2016) que se dedicaram a descrever como foi elaborado um simulador no software GeoGebra. Para os autores deste trabalho entende-se como simulador um modelo que recria alguma situação que possa ser real ou fictícia, no qual podem-se manipular pelo menos uma de suas variáveis (HONEY, HILTON, 2011). Neste caso, o modelo é computacional porque foi construído na interface gráfica de um software (RUBIO, PRIETO, ORTIZ; 2016). Do trabalho de Diaz e Rubio (2016), centra-se a atenção no contexto em que foi desenvolvido, já que foi realizado com fins educacionais, e na descrição de como foi construído o simulador computacional. Tal descrição foi estruturada em quatro partes:

a) Criação do movimento a ser simulado.

b) Colocação da imagem de um objeto que faz o movimento.

c) Organização do painel de controle das variáveis.

d) Contextualização do simulador.

Em cada uma destas partes se construiu uma etapa do simulador. Nos pontos 1 e 3 se apresenta a teoria física e matemática que foi utilizada para a construção do objeto e em 2 e 4 se explica como foi ambientado para que representasse um simulador de uma situação particular. Além disso, para a adaptação do simulador em uma situação particular foram utilizados conceitos matemáticos para encontrar uma ambientação adequada. Destaca-se que, nesse simulador, o usuário pode estudar o fenômeno subjacente numa situação particular, podendo:

a) Manipular certas variáveis que acontecem nele;

b) Olhar a variação entre as variáveis;

c) Estudar a relação que existem entre as variáveis.

Para esta pesquisa, no contexto do trabalho, essas quatros partes foram analisadas desde a perspectiva da Transposição Didática para identificar as características dessa teoria na construção deste recurso digital, e serem apresentadas no corpo deste trabalho. Tem-se o intuito de oferecer uma reflexão que envolva, além dos simuladores, outros tipos de recursos digitais que também possam ser construídos com o GeoGebra.

\section{GeoGebra}

O GeoGebra é considerado um software livre de Matemática Dinâmica (MD) que foi traduzido em uma quantidade considerável de idiomas e que pode ser utilizado em qualquer sistema computacional e móvel. Diz-se que é um programa de MD pois contém de forma dinâmica tópicos de Geometria, Álgebra, Planilha de Cálculo, Gráficos, Estatística e Cálculo, 
os quais podem ser usados isolados ou combinados. Atualmente, o software se encontra na versão 6.

Além das qualidades de acessibilidade do software para os usuários e da sua pouca complexidade na familiarização com as ferramentas, a característica de usar diferentes aspectos para o estudo de conceitos Matemáticos em diferentes representações, faz dele um programa que permite o estudo de uma forma diferenciada, favorecendo a organização de várias representações em uma mesma interface. Essa particularidade do GeoGebra tem gerado certas mudanças nas capacidades de experimentação e visualização durante o estudo de um objeto matemático, o que tem promovido novas formas de produção de conhecimento matemático. Esses atributos do software têm feito dele uma ferramenta potencial para a construção de Objetos de Aprendizagem para o ensino e aprendizagem de conteúdos particulares da Educação Matemática (SOBREIRA; DA SILVA, 2016).

\section{Objetos de aprendizagem (OA)}

O GPTEM, grupo de pesquisa do qual fazem parte os autores deste texto, vem discutindo e aprofundando compreensões sobre recursos digitais chamados "Objetos de Aprendizagem", com o intuito de aprofundar conhecimentos sobre eles e contribuir com a comunidade interessada. As discussões entre os componentes do grupo possibilitaram a consolidação de uma definição para estes recursos tecnológicos digitais. Para o GPTEM um OA é: [...] "qualquer recurso virtual multimídia, que pode ser usado e reutilizado como intuito de dar suporte a aprendizagem de um conteúdo específico, por meio de atividade interativa, apresentada na forma de animação ou simulação" (KALINKE; BALBINO, 2016, p. 25).

Com base no trabalho desenvolvido por Diaz e Rubio (2016) e na definição utilizada pelo GPTEM, compreende-se que o simulador em questão pode ser considerado como um Objeto de Aprendizagem. Esta compreensão se justifica por diversas razões, entre as quais se destacam as apresentadas a seguir:

a) É um recurso virtual, construído no software GeoGebra;

b) Foi criado para dar suporte a um conteúdo em específico, neste caso o Movimento Retilíneo Uniforme;

c) Promove uma atividade interativa, uma vez que para ser explorado, o usuário deve indicar valores de variáveis para iniciar, bem como tem as possibilidades de pausar ou recomeça a simulação;

d) Faz a simulação de um Movimento Retilíneo Uniforme.

Em relação aos Objetos de Aprendizagem que são simuladores, Kalinke e Balbino (2016, p. 28) comentam que eles "permitem um controle rígido e em mesmo tempo real sobre seu representante no modelo da situação simulada, de estar em interação pessoal e imediata com a mesma". A este respeito, Lévy (1993) comenta que:

\footnotetext{
O conhecimento por simulação, menos absoluto que o conhecimento teórico, mais operatório, mais ligado às circunstâncias particulares de seu uso, junta-se assim ao ritmo sociotécnico específico das redes informatizadas: o tempo real. A simulação por computador permite que uma pessoa explore modelos mais complexos e em maior número do que se estivesse reduzido aos recursos de sua imagística mental e de sua memória de curta prazo, mesmo se reforçadas por este auxiliar por demais estático que é o papel. A simulação, portanto, não remete a qualquer pretensa irrealidade do saber ou da relação com o mundo, mas antes a um aumento dos poderes da imaginação e da intuição (LÉVY, 1993, p. 127).
} 
Neste sentido, o simulador "Movimiento Rectilíneo Uniforme" foi desenvolvido para representar uma situação do mundo real, como é destacado na Figura 1. O ambiente desse simulador representa a situação na qual um carro faz um trajeto durante um determinado espaço de tempo. Antes de começar o caminho, o usuário pode indicar qual será a velocidade do veículo e ao clicar no botão de play, ele poderá observar o comportamento das diferentes variáveis que participam nesse fenômeno. Além disso, como ele é feito para o estudo do Movimento Retilíneo Uniforme, permite analisar os gráficos associados à relação entre a distância percorrida pelo veículo e o tempo, e entre a velocidade e o tempo, o que colabora para um estudo mais detalhado do fenômeno.

Figura 1 - Aparência do simulador "Movimiento Rectilíneo Uniforme"

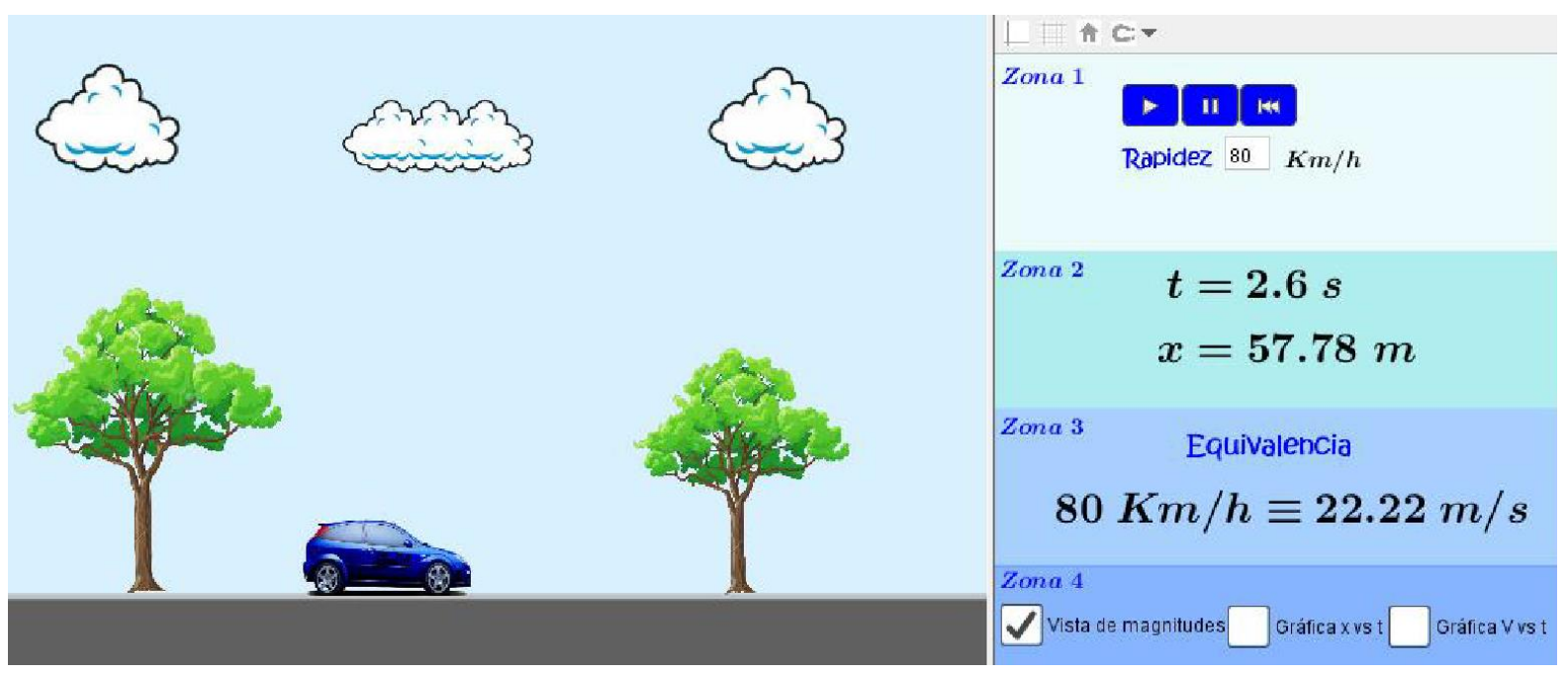

Fonte: Diaz e Rubio (2016)

A seguir serão descritos como os processos e as ações da Transposição Didática estão presentes na elaboração desse Objeto de Aprendizagem no GeoGebra e suas contribuições na Educação Matemática.

\section{A transposição didática em um objeto de aprendizagem}

Para compreender as ideias que permitem perceber a Transposição Didática na elaboração de um Objeto de Aprendizagem, este trabalho se apoia no texto escrito por Diaz e Rubio (2016), destacando as partes nas quais se pode perceber questões relativas à Transposição Didática na descrição da construção desse objeto.

$\mathrm{Na}$ revisão do trabalho, nesta perspectiva teórica, é possível perceber uma primeira evidência quando as autoras comentam que o simulador é indicado para ser utilizado considerando-se o nível da turma e o conteúdo a ser estudado naquele momento, segundo o currículo escolar. Em relação à turma, foi apontado pelas autoras que ele é indicado para o quarto ano da Educação Média da Venezuela (que seria o equivalente ao segundo ano do Ensino Médio do Brasil) e o conteúdo a ser estudado é Movimento Retilíneo Uniforme. 
Para a elaboração do simulador, considerou-se o ano letivo que ia ter o laboratório e o conteúdo que devia-se estudar nesse momento. Em quanto ao ano, foi o $4^{\circ}$ de Educação Média [...]. Respeito ao conteúdo, foi selecionado o Movimento Retilíneo Uniforme, portanto, o simulador incluiu: (i) a recreação deste movimento em um contexto determinado e (ii) a elaboração das gráficas associadas a tal movimento, rapidez x tempo e distância x tempo (DIAZ; RUBIO, 2016, p. 157168. Tradução nossa).

Essas indicações podem ser relacionadas às ideias da Transposição Didática nos quesitos de 'seleção' do saber, uma vez que indicam em que momento e em que turmas devem ser utilizados. Portanto, pode-se dizer que se trata um conteúdo que já havia passado pela Programação e Publicidade, porque é indicado para turmas específicas e para momentos em particular, segundo o currículo previamente previsto.

Seguindo a análise, em Diaz e Rubio (2016, p. 158) pode-se evidenciar a 'redução' das informações porque, para a construção do simulador, recria-se o tipo de movimento e se apresentam as informações gráficas associadas à velocidade $\mathrm{x}$ tempo e distância $\mathrm{x}$ tempo. Considera-se que estas informações podem ser compreendidas como 'redução' porque se limitou, na construção do OA, a simular o movimento e a representar as informações gráficas associadas a ele.

Ainda em Diaz e Rubio (2016), comenta-se que o movimento é recriado com o uso de um simulador de automóvel, que anda em linha reta em uma avenida, supondo que se trata de "uma situação "familiar" para os estudantes, incluindo alguns termos associados a ele, por exemplo, que o veículo vai a $80 \mathrm{Km} / \mathrm{h}$, tem recorrido $100 \mathrm{~m}$ ou que demorou $15 \mathrm{~s}$ ” (p. 158 . Tradução nossa). Nestes aspectos se percebe como a 'simplificação' do conteúdo se faz evidente pelo uso da recontextualização do fenômeno em uma situação particular, tentando facilitar o desenvolvimento e apresentação dos conteúdos.

Já na parte que se descreve como foi elaborado o OA (DIAZ; RUBIO, 2016), destacam que, inicialmente, fez-se a recriação do Movimento Retilíneo Uniforme e para isso, "utilizou-se a expressão $|x|=|v| \cdot t$ que permite determinar a distância percorrida por um móvel" (p. 160. Tradução nossa), com uma determinada rapidez e o tempo que demorou para percorrer a distância em questão (Figura 2). Não se dará detalhes de como isso foi construído no software, uma vez que isso pode ser encontrado no trabalho de Diaz e Rubio (2016). O que se destaca aqui é que a recriação desse movimento, ou seja, a simulação, foi realizada a partir de suas ideias conceituais, o que poderia representar uma 'reformulação' do saber em uma situação contextualizada, sem perder a essência conceitual desse fenômeno, tal como pressuposto na Transposição Didática. 
Figura 2 - Representação do movimento.

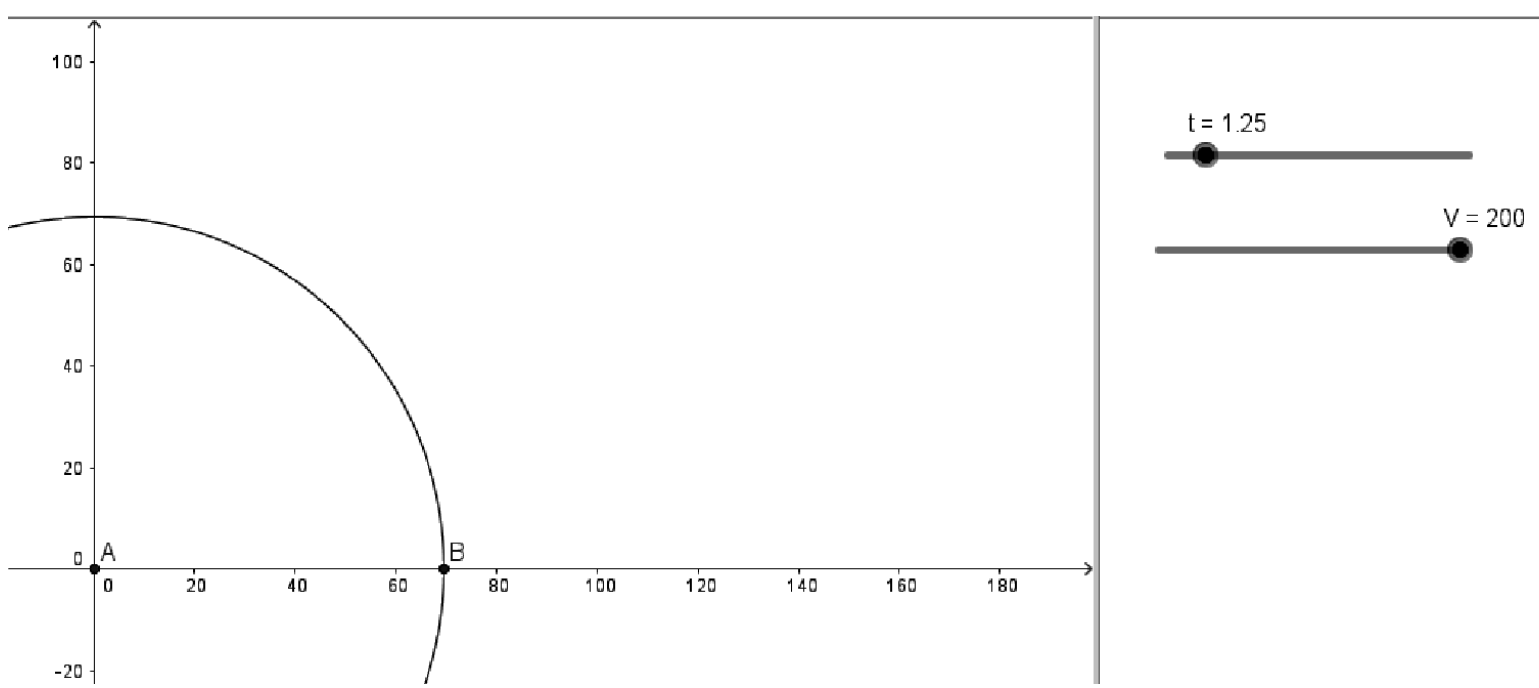

Fonte: Diaz e Rubio (2016)

Diaz e Rubio (2016) ainda explicam como foram criadas as apresentações gráficas associadas à velocidade $\mathrm{x}$ tempo e distância $\mathrm{x}$ tempo. Elas foram geradas a partir dos valores das variáveis inter-relacionadas, as quais foram consideradas como pares ordenados (Figura 3). Neste caso, pode-se considerar que há uma 'reformulação' e também 'controle social da aprendizagem' porque, embora estejam imersas em uma situação particular, as ideias conceituais necessárias para criar as apresentações gráficas que representam um fenômeno se conservam na construção do simulador.

Figura 3 - Gráficas associadas ao fenómeno

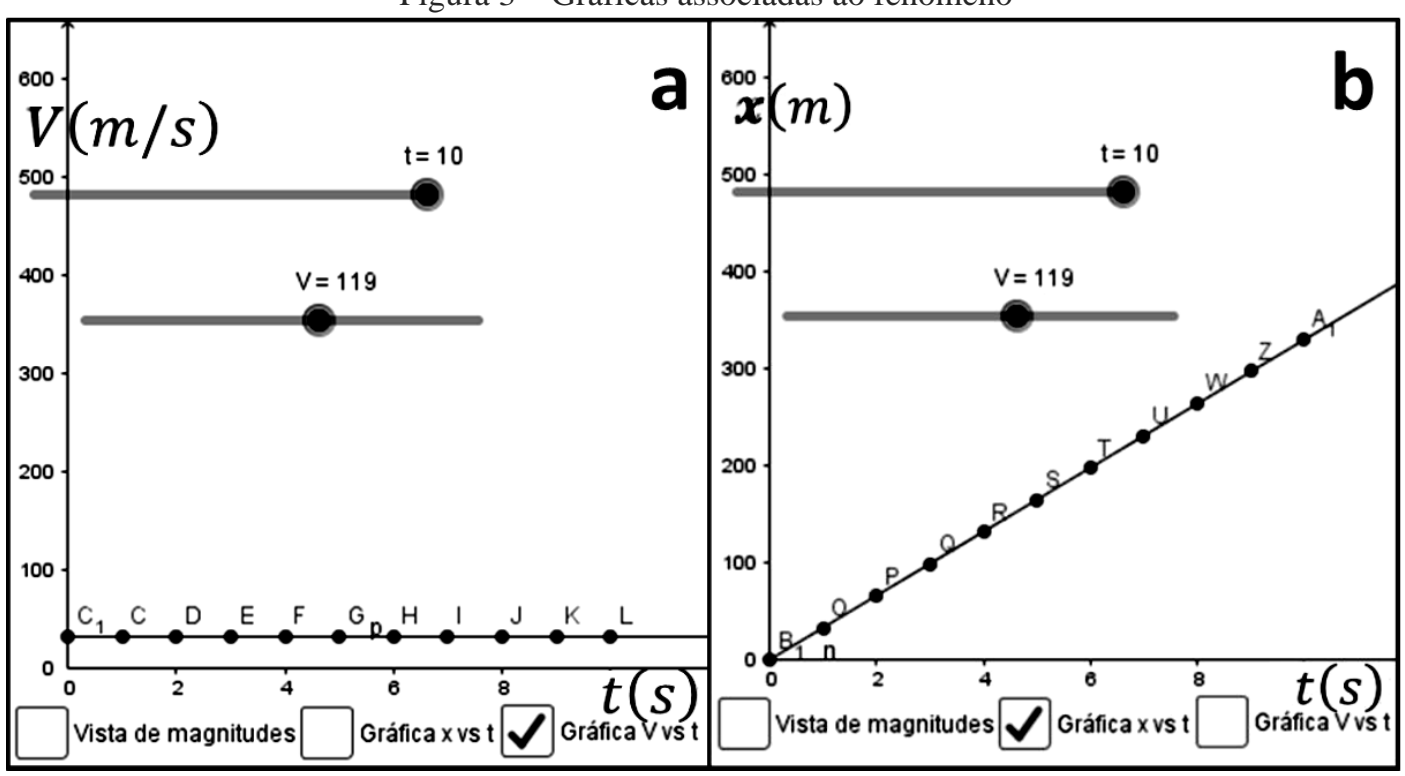

Fonte: Adaptado de Diaz e Rubio (2016)

Finalmente, sobre as contribuições do OA na Educação Matemática, identifica-se que, mesmo sendo ele construído para o estudo de um conteúdo da Física, as bases da 
elaboração foram essencialmente conceitos matemáticos (Figura 4). Essa qualidade permite que o objeto seja utilizado em outros contextos, por exemplo, para o estudo da função linear. Neste caso, poder-se-ia usá-lo, uma vez que o recurso permite a abordagem desse conteúdo matemático em uma situação particular, permitindo estabelecer a variável independente, perceber a variação nas variáveis dependentes, tabular os dados que estejam em análise e estudar o comportamento dos gráficos associados à função que se modificam segundo os dados das variáveis.

Figura 4 - Colocação do carro que faz o movimento com a ajuda de objetos geométricos

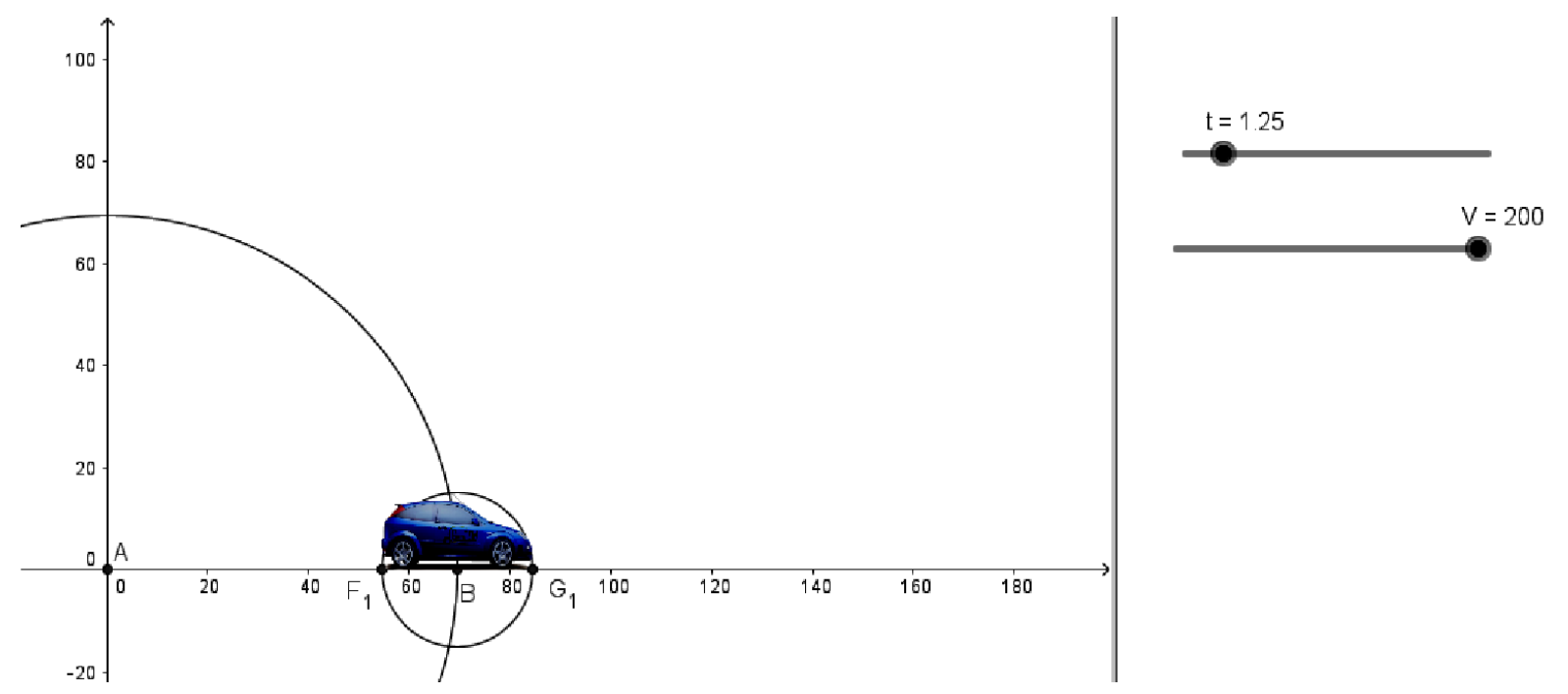

Fonte: Diaz e Rubio (2016)

\section{Reflexões Finais}

$\mathrm{Na}$ introdução deste texto foi indicado que se faria uma descrição de como certos processos e ações da Transposição Didática estão presentes na construção do Objeto de Aprendizagem "Movimento Rectilíneo Uniforme". Para tal descrição se utilizou o trabalho de Diaz e Rubio (2016) que descreve como se fez a elaboração desse simulador no software GeoGebra, trabalho que foi analisado desde a perspectiva teórica adotada.

Na descrição realizada, pode-se ver como as ações que acontecem numa Transposição Didática: 'selecionar', 'reduzir', 'simplificar' e 'reformular' estão presentes em certas decisões tomadas para a elaboração do Objeto de Aprendizagem. Além disso, também se destacam alguns dos processos presentes nesta perspectiva teórica: 'Descontextualização', 'Programação', 'Controle social da aprendizagem' e 'Publicidade'. Embora não seja evidente o processo de 'despersonalização', não significa que ela não esteve presente na elaboração do simulador. De modo análogo, não se pode afirmar, definitivamente, que a intenção da Transposição Didática esteve presente na construção do AO, já que não foi declarado que ele foi construído observando essa teoria.

Entretanto, é evidente que certas questões desta teoria se podem manifestar na elaboração destes materiais, direcionados para uso nas aulas, o que nos pode levar a considerar que na utilização das TD na Educação Matemática é possível evidenciar certas propriedades da Transposição Didática. Isso também poderia ser interessante no caso da Educação em Ciências já que, embora o objeto tenha sido elaborado em um software de MD, ele pode ser utilizado tanto para a Matemática como para o estudo de um fenômeno físico. 
Esta questão pode ser atribuída ao GeoGebra, devido a que nele, como foi mostrado, podese trabalhar com expressões algébricas cujas variáveis podem ser representadas no mesmo software. Tais expressões podem ser próprias do estudo de questões matemáticas ou aquelas que correspondem ao estudo de algum fenômeno científico que se possa descrever com uma expressão matemática.

Em relação às contribuições de um Objeto de Aprendizagem elaborado com o GeoGebra, pode-se dizer que se tem certas especificidades deste tipo de recursos construídos com o GeoGebra. No primeiro lugar, o caráter dele ser reutilizável, que permite que possa ser adaptado a uma aula de Matemática, embora tenha sido construído para um conteúdo da Física. Além disso, graças à característica livre do software, pode-se fazer mudanças no OA para atender às necessidades específicas de cada professor. Ainda, o uso de ideias Matemáticas para a elaboração do OA se deve ao GeoGebra ser direcionado para trabalhar com conceitos Matemáticos e, para o uso das ferramentas disponíveis no programa, exigir do usuário conhecimentos matemáticos pré-existentes ou a exploração destes conhecimentos. Finalmente, destaca-se a possibilidade de ser utilizado em diferentes sistemas computacionais e móveis, o que permite o uso destes tipos de recursos com facilidades nas salas de aula.

Como resultado, podemos também perceber e valorizar o papel do professor na Transposição Didática quando se usa as TD. Ele tem um papel fundamental na organização dos conteúdos para que eles cheguem até os estudantes de forma simples, mas que garantam a essência das concepções e ideias dos saberes que estão sendo objeto de ensino. Pode-se perceber, finalmente, que na elaboração de um OA os processos e ações da Transposição Didática se fazem evidente, mesmo ela não sendo considerada como a base teórica original.

\section{Agradecimentos}

À CAPES, ao CNPq e ao Programa de Pós-graduação em Educação em Ciência e em Matemática da Universidade Federal do Paraná.

\section{Referências}

ALMOULOUD, S. A. Informática e educação matemática. Revista de Informática Aplicada, v. 1, n. 1, 2010. Disponível em: http://ria.net.br/index.php/ria/article/view/95/90. Acesso em: 19 out. 2018.

ARTIGUE, M. Tecnología y enseñanza de las matemáticas: desarrollo y aportes de la aproximación instrumental. Cuadernos de Investigación y Formación en Educación Matemática, n. 8, p. 13-33. 2011. Disponível em: https://revistas.ucr.ac.cr/index.php/cifem/article/view/6948. Acesso em: 15 jan. 2017.

CARDELLI, J. Reflexiones críticas sobre el concepto de Transposición Didáctica de Chevallard. Cuadernos de antropología social, n. 19, p. 49-61. 2004. Disponível em: http://www.scielo.org.ar/scielo.php?script=sci_arttext\&pid=s1850-275x2004000100004. Acesso em: 03 out. 2018.

CHEVALLARD, Yves. La transposición didáctica. Del saber sabio al saber enseñado, 1991. Disponível em: 
https://www.researchgate.net/publication/242760000_La_transposicion_didactica_Del_sab er_sabio_al_saber_ensenado. Acesso em: 03 out. 2018.

DIAZ, S.; RUBIO, L. Movimiento Rectilíneo Uniforme con GeoGebra. Un Simulador para la enseñanza de la Física. Em Prieto, J.L. e Gutiérrez, R.E. (Comps.). Memorias del II Encuentro de Clubes GeoGebra del Estado Zulia. Maracaibo, Venezuela: A.C. Aprender en Red, p. 156-168. 2016. Disponível em: https://www.researchgate.net/publication/328229162_MOVIMIENTO_RECTILINEO_UN IFORME_CON_GEOGEBRA_UN_SIMULADOR_PARA_LA_ENSENANZA_DE_LA_ FISICA. Acesso em: $01 \mathrm{dez} .2018$.

FERNÁNDEZ CARABALLO, A. M. Sobre la propuesta epistemológica de Chevallard. Revista Fermentario, n. 6, p. 1-19. 2012. Disponível em: http://fermentario.fhuce.edu.uy/index.php/fermentario/article/view/97. Acesso em: 03 out. 2018.

GÓMEZ MENDOZA, M. A. La transposición didáctica: historia de un concepto. Revista Latinoamericana de Estudios Educativos, Colombia, v. 1, n. 1, p. 83-115. 2005. Disponível em: http://www.redalyc.org/html/1341/134116845006/. Acesso em: 03 out. 2018.

HONEY, M. A.; HILTON, M. Learning science through computer games and simulations. The National Academies Press, Washington, D.C., 2011.

JARDIM, L. de M.; CAMARGO, S.; ZIMER, T. T. B. Transposição Didática no Ensino de Ciências: Diferentes Olhares. In: XI Congresso Nacional de Educação. 2015. Disponível em: http://educere.bruc.com.br/arquivo/pdf2015/17323_10412.pdf. Acesso em: 03 out. 2018.

KALINKE, M. A. e BALBINO O. R. Lousas Digitais e Objetos de Aprendizagem. Em M. A. Kalinke y L. F. Mocrosky (org.), A Lousa Digital y Outras Tecnologias na Educação Matemática. Curitiba, Brasil: Editora CVR. 2016. p. 13-31.

LÉVY, P. As tecnologias da inteligência: o futuro do pensamento na era da informática. Rio de Janeiro: Editora 34, 1993.

MONTEIRO, D. M.; KRÜGER, M. F. A ciência como expressão da cultura e a transposição didática. In: Encontro Nacional de Pesquisa em Educação em CiênciasVII ENPEC, p. 1-12. 2009.

MORA CASTIBLANCO, J. E. La Transposición Didáctica del Saber Sabio al Saber Enseñado. Autor: Yves Chevallard. Revista Góndola, Enseñanza y Aprendizaje de las Ciencias, Bogotá, v. 9, n. 2, p. 97-100. 2014. Disponível em: https://revistas.udistrital.edu.co/ojs/index.php/GDLA/article/view/8012. Acesso em: 1 dez. 2018.

MOTTA, M. S. Tecnologias educacionais e estágio supervisionado: um estudo de caso na licenciatura em matemática. Educação \& Tecnologia, v. 21, n 2, p. 50-65. 2018. 
Disponível em: https://periodicos.cefetmg.br/index.php/revista-et/article/view/752. Acesso em: 19 out. 2018.

NEVES, K. C. R.; BARROS, R. M. O. Diferentes olhares acerca da transposição didática. Investigações em Ensino de Ciências, v. 16, n. 1, p. 103-115. 2016. Disponível em: https://www.if.ufrgs.br/cref/ojs/index.php/ienci/article/view/249. Acesso em: 03 out. 2018.

OBATA, J. Y.; MOCROSKY, L. F.; KALINKE, M. A. Tecnologia, educação e educação tecnológica: heranças e endereçamentos. \#Tear: Revista de Educação, Ciência e Tecnologia, v. 7, n. 1, p. 1-22. 2018. Disponível em: https://periodicos.ifrs.edu.br/index.php/tear/article/view/2727. Acesso em: 13 out. 2018.

PAIS, L.C. Didática da Matemática: uma análise da influência francesa. Rio de Janeiro, Brasil: Autêntica, 2001.

PAZUCH, V.; BATTISTI, I. K.; NEHRING, C. M. Contribuições da Investigação Matemática para o Processo de Ensinar e Aprender Matemática com Tecnologia Informática. Experiências em Ensino de Ciências, v, 6, n. 3, p. 54-62. 2011. Disponível em: http://if.ufmt.br/eenci/artigos/Artigo_ID159/v6_n3_a2011.pdf. Acesso em: 20 out. 2018

RAMÍREZ BRAVO, R. Aproximación al concepto de transposición didáctica. Revista Folios, n. 21, p. 33-45. 2005. Disponível em: https://www.redalyc.org/pdf/3459/345955978004.pdf. Acesso em: 03 out. 2018.

RIVEROS, V; BERNAL, M. I. Mendoza; CASTRO, R. Las tecnologías de la información y la comunicación en el proceso de instrucción de la matemática. Quórum académico, Universidad del Zulia, v. 8, n. 15, p. 111-130. 2011. Disponível em: https://dialnet.unirioja.es/servlet/articulo?codigo=3999014. Acesso em: 13 out. 2018.

RUBIO, L.; PRIETO, J.; ORTIZ, J. La matemática en la simulación con GeoGebra. Una experiencia con el movimiento en caída libre. IJERI: International Journal of Educational Research and Innovation, n. 5, p. 90-111, 2016.

VERRET M. Le temps des études, Paris, Librairie Honoré Champion. 1975.

VILLA-OCHOA, J. Producción de conocimientos por los futuros profesores. Un ejemplo con tecnologías digitales. Em. A. Urieles; A. Reyes e J. L. Rodriguez (org.). Memorias Encuentro Internacional de Matemáticas. Barranquilla: Universidad del Atlántico, p. 46. 2016. Disponível em: http://funes.uniandes.edu.co/8516/. Acesso em: 13 out. 2018.

VILLARREAL, M. E. Tecnologías y educación matemática: necesidad de nuevos abordajes para la enseñanza. Virtualidad, Educación y Ciencia, v. 3, n. 5, p. 73-94. 2012. Disponível em: https://revistas.unc.edu.ar/index.php/vesc/article/view/3014. Acesso em: 15 ago. 2016.

Recebido em julho de 2019. Aprovado em setembro de 2019. 